\title{
1 Submerged macrophytes affect the temporal variability of aquatic ecosystems
}

4 Moritz D. Lürig ${ }^{1,2,3}$, Rebecca J. Best ${ }^{2,4}$, Vasilis Dakos ${ }^{5}$, Blake Matthews ${ }^{2}$

6 Running head: Macrophytes affect variability of ecosystems

$8{ }^{1}$ Eawag Kastanienbaum, Department of Aquatic Ecology, Seestr. 79, 6047 Kastanienbaum,

9 Switzerland

$10{ }^{2}$ Eawag Kastanienbaum, Department of Fish Ecology and Evolution, Seestr. 79, 6047

11 Kastanienbaum, Switzerland

$12{ }^{3}$ ETH Zürich, Center for Adaptation to a Changing Environment (ACE), Inst. of Integrative 13 Biology, CH-8092 Zürich, Switzerland

$14{ }^{4}$ School of Earth and Sustainability, Northern Arizona University, Flagstaff, AZ 86011 USA

$15{ }^{5}$ ISEM, University of Montpellier, CNRS, EPHE, IRD, Montpellier, France

16

17 Corresponding author:

18 Moritz D. Lürig, Eawag, Seestr. 79, 6047 Kastanienbaum

19 Email: moritz.luerig@gmail.con

Tel.: +41774877934

22 keywords: phytoplankton, competition, variance, mesocosms, DOC, metabolism

This document is the accepted manuscript version of the following article:

Lürig, M. D., Best, R. J., Dakos, V., \& Matthews, B. (2021). Submerged macrophytes affect the temporal variability of aquatic ecosystems. Freshwater Biology. https://doi .org/10.1111/fwb.13648 


\section{Abstract}

1. Submerged macrophytes are important foundation species that can strongly influence the structure and functioning of aquatic ecosystems, but only little is known about the temporal variation and the timescales of these effects (i.e. from hourly, daily, to monthly).

2. Here, we conducted an outdoor experiment in replicated mesocosms (1000 L) where we manipulated the presence and absence of macrophytes to investigate the temporal variability of their ecosystem effects. We measured several parameters (chlorophyll-a, phycocyanin, dissolved organic matter $[\mathrm{DOM}]$, and oxygen) with high-resolution sensors (15 min intervals) over several months (94 days from spring to fall), and modelled metabolic rates of each replicate ecosystem in a Bayesian framework. We also implemented a simple model to explore competitive interactions between phytoplankton and macrophytes as a driver of variability in chlorophyll-a.

3. Over the entire experiment, macrophytes had a positive effect on mean DOM concentration, a negative effect on phytoplankton biomass, and either a weak or no effect on mean metabolic rates, DOM composition, and conductivity. We also found that macrophytes increased the variance of DOC composition and metabolic rates, and, at some times of the observed period, increased the variance of phytoplankton biomass and conductivity. The observation that macrophytes decreased the mean but increased the variance of phytoplankton biomass was consistent with the model that we implemented.

4. Our high-resolution time series embedded within a manipulative experiment reveal how a foundation species can affect ecosystem properties and processes that have characteristically different timescales of response to environmental variation. Specifically, our results show how macrophytes can affect short-term dynamics of algal 

ecosystem metabolism.

\section{Introduction}

51 Decades of research on submerged macrophytes have documented how these aquatic plants can influence a suite of ecosystem properties and processes (Carpenter \& Lodge, 1986; Jeppesen et al., 1997; Huss \& Wehr, 2004; Reitsema, Meire \& Schoelynck, 2018). Acting as foundation species (Dayton, 1972; Ellison et al., 2005), macrophytes create and maintain habitats for other species, affect species interactions, and influence the dynamics of matter and energy in freshwater ecosystems (Carpenter \& Lodge, 1986; Jeppesen et al., 1997). Populations of individual macrophyte species, as well as species assemblages, can also influence how aquatic ecosystems respond to environmental change and the propensity of ecosystems to shift between alternative stable states in shallow lakes (Scheffer et al., 1993; Blindow, Hargeby \& Andersson, 1998; Faafeng \& Mjelde, 1998). Importantly, while the net ecosystem effects of macrophytes in contrasting equilibrium states are well studied, much less is known about how macrophytes affect the temporal dynamics of ecosystem properties and processes over timescales ranging from hours, to days, to months (Mitchell \& Rogers, 1985; Madsen \& Adams, 1988; Iacarella et al., 2018). High-resolution times series that capture both mean and variance responses of aquatic ecosystems are essential for predicting the effects of environmental change on aquatic ecosystems (Reitsema et al., 2018; Hillebrand et al., 2018) and improving their management in light of increasing disturbance and climate variability (Spears et al., 2017).

The strong and persistent ecosystem effects of macrophyte communities are often linked to their competitive interactions with phytoplankton communities for dissolved nutrients and light (Carpenter \& Lodge, 1986; Scheffer et al., 1993). In shallow lakes, the positive 
feedback between light transmission and macrophyte biomass is an important reason why macrophytes help maintain a clear water state over a wide range of nutrient loading (Scheffer et al., 1993, 2003; Blindow et al., 1998). Many types of macrophytes are efficient at taking up nutrients from the water and, if rooted, from the sediment, which can limit phytoplankton growth at low to intermediate nutrient loading (Yamamichi et al., 2018). Furthermore, macrophytes can reduce fish predation pressure on the zooplankton communities that graze on phytoplankton (Jeppesen et al., 1997), and can also produce allelopathic chemicals that inhibit phytoplankton growth (Gross, 2003; Hilt \& Gross, 2008; Nakai et al., 2012). While it is known that such mechanisms can contribute to the positive feedbacks that help maintain lakes in a clear water state (Kéfi, Holmgren \& Scheffer, 2016; Iacarella et al., 2018), surprisingly little is known about the seasonal dynamics of these interactions (Carpenter, 1988; Benedetti-Cecchi, 2003). This is a problematic knowledge gap because the variance of ecosystem properties is increasingly recognized as an important dimension of overall ecosystem resilience (Cottingham \& Carpenter, 1998; Benedetti-Cecchi, 2003; Scheffer et al., 2009; Vasseur et al., 2014; Zelnik, Arnoldi \& Loreau, 2018).

In addition to the effects on phytoplankton dynamics, macrophytes are known to affect the amount and composition of dissolved organic matter (DOM) (Bolan et al., 2011; Kellerman et al., 2015), which is a diverse mixture of low and high molecular weight components of different structure and composition (Bolan et al., 2011; Kellerman et al., 2015). In the clear water state, phototrophic organisms such as macrophytes, phytoplankton and bacteria produce

92 low weight dissolved organic carbon (DOC) compounds such as carbohydrates that are 93 byproducts of photosynthesis (Carpenter \& Lodge, 1986; Retamal et al., 2007; Bolan et al., 2011; Reitsema et al., 2018). Macrophytes can both directly produce DOC, and indirectly reduce it by stimulating higher rates of DOC degradation from epiphytic bacteria (Catalán, 
different compositions of DOM in aquatic ecosystems (Reitsema et al., 2018) it is important to experimentally test how macrophytes can simultaneously affect the mean and variance of DOM concentration and composition (Findlay \& Sinsabaugh, 2003; Catalán et al., 2014; Reitsema et al., 2018), and to consider such effects in models of ecosystem resilience to nutrient perturbation (Kéfi et al., 2016; Spears et al., 2017).

DOC dynamics driven by competitive interactions between macrophytes and phytoplankton can also alter ecosystem metabolism (Mitchell, 1989; Kaenel, Buehrer \& Uehlinger, 2000; Findlay \& Sinsabaugh, 2003; Reitsema et al., 2018). Growth and decay of macrophyte tissue can strongly affect metabolic rates of shallow lakes, depending on plant density, diversity and lake depth (Żbikowski et al., 2019). In shallow lakes with a given nutrient load, ecosystem productivity is typically higher when macrophytes are dominant over phytoplankton (Wetzel, 1964; Carpenter \& Lodge, 1986; Brothers et al., 2013). Macrophytes are known to be efficient photosynthesizers (Kaenel et al., 2000), but also provide additional substrate for the growth of autotrophic periphyton and bacteria (Wetzel \& Søndergaard, 1998; Brothers et al., 2013). Additionally, the effects of macrophytes on the dynamics of DOC accumulation and decomposition can affect shifts between net autotrophy and net heterotrophy (Mitchell \& Rogers, 1985; Madsen \& Adams, 1988; Nielsen et al., 2013). Overall, the potential effects of interactions between macrophytes and phytoplankton on whole ecosystem metabolism are increasingly well documented. However, the ability of macrophytes to resist or moderate perturbations to ecosystem metabolism in the context of global change depends on the relative importance of the described mechanisms and the temporal scale on which they each occur (Zelnik et al., 2018). To our knowledge, only a few studies have investigated the effects of competition for light and nutrients between macrophytes and phytoplankton on dynamics of DOC and metabolism at the temporal resolution necessary to understand how they interact (Benedetti-Cecchi, 2003; Zelnik et al., 2018). 
123 oligotrophic aquatic ecosystems in 1000L mesocosms over an entire growing season. We

124 manipulated the presence and absence of a macrophyte assemblage consisting of two common

125 species, Myriophyllum spicatum and Chara tomentosa, and quantified several biotic (two

126 phytoplankton pigments) and abiotic (temperature and conductivity, dissolved oxygen,

127 dissolved organic matter) properties at high temporal resolution (15 min). We used this data

128 set to test 3 hypotheses. First, we predicted that macrophytes would be able to suppress

129 phytoplankton biomass across seasonal variation in light and temperature. Second, we

130 predicted that macrophytes would increase overall rates of ecosystem metabolism because they

131 are known to be efficient photosynthesizers. Third, we predicted that macrophytes should

132 impact not only mean ecosystem properties such as phytoplankton biomass, DOM, and

133 metabolism, but also their temporal variance in response to continual changes in resource

134 availability. For this last hypothesis, we also tested whether we could generate observed

135 contrasts in variability using a simple model of competitive interactions between phytoplankton

136 and macrophytes. We compare our findings with previous empirical work and discuss the broad

137 functional spectrum of macrophytes as foundation species in shallow lake ecosystems.

\section{Material and methods}

\section{Experimental design and setup}

140 In an outdoor mesocosm experiment, we manipulated the presence or absence of an assemblage

141 of macrophytes including Myriophyllum spicatum (hereafter Myriophyllum), a perennial

142 vascular plant that grows vertically towards the water surface forming a canopy, and Chara

143 tomentosa (hereafter Chara), a green algae that forms tufts of calcium carbonate encrusted

144 stems (typically $<30 \mathrm{~cm}$ ) on the sediment surface. We chose this assemblage because both 
145 species are common in Europe and other parts of the world, they commonly occur together in 146 macrophyte assemblages, and their strong influence on lake ecosystems has been previously 147 documented (Van den Berg et al., 1998; Ibelings et al., 2007; Hilt \& Gross, 2008; Nakai et al., 148 2012).

149 We set up the experiment on a site next to Eawag Kastanienbaum (eight tanks total) 150 with four pairs of $1000 \mathrm{~L}$ mesocosms $(1 \mathrm{x} 1 \mathrm{x} 1 \mathrm{~m})$, with each pair consisting of a mesocosm with $(\mathrm{M}+)$ and without (M-) a macrophyte assemblage (Fig. 1). To prepare the mesocosms, we first established a $2 \mathrm{~cm}$ thick layer of limestone gravel from a local quarry (2-4 mm grain size) and a $1 \mathrm{~cm}$ thick layer of fine, oligotrophic sediment (Fiskal et al., 2019) that we collected from a vegetation free area of Lake Lucerne $\left(47^{\circ} 00^{\prime} 33.3^{\prime \prime} \mathrm{N} 8^{\circ} 18^{\prime} 33.8^{\prime \prime} \mathrm{E}\right)$. Afterwards the mesocosms were filled with water from Lake Lucerne, an oligotrophic, clear water lake (Fiskal et al., 2019), which was pumped up from an inlet in $40 \mathrm{~m}$ depth and left in the mesocosms for two weeks to allow the sediment to settle and the mesocosm community to assemble. On May 25th, 2015, we collected Myriophyllum from a clear water stream in Oberriet $\left(47^{\circ} 19^{\prime} 55.5^{\prime \prime} \mathrm{N} 9^{\circ} 34^{\prime} 43.9^{\prime \prime} \mathrm{E}\right)$ and kept the plants overnight in additional outdoor mesocosms onsite. The following day we

160 collected Chara from a single location in Lake Lucerne $\left(47^{\circ} 00^{\prime} 06.8^{\prime \prime} \mathrm{N} 8^{\circ} 20^{\prime} 02.7^{\prime \prime} \mathrm{E}\right)$ and 161 planted both species in the mesocosms. To do so we divided all the macrophyte material manually (on a large and moist plastic sheet) into 18 similar sized portions based on either an equal number of shoots (i.e. for (Myriophyllum), or similarly sized tufts (i.e. for Chara). We used 10 portions to quantify the initial plant biomass (cleaned of sediment, infauna removed, 165 biomass dried for 48 hours at $45^{\circ} \mathrm{C}$ ) and added 4 portions to the $\mathrm{M}+$ tanks. Given that both 166 plant species were collected from clear water sites and planted in mesocosms filled with oligotrophic water, we assumed that growing conditions were similar for both plant species. 
170 enclosures in the middle of the water column for two weeks. On July 4th, we added $20 \mu \mathrm{g} * \mathrm{~L}^{-}$

$171{ }^{1}$ of $\mathrm{P}$ and $144.7 \mu \mathrm{g} * \mathrm{~L}^{-1}$ of $\mathrm{N}$ (i.e. Redfield ratio) to every mesocosm to supplement the Lake

172 Lucerne source water with nutrients. Over the course of the experiment we measured dissolved

173 nutrient concentrations in the mesocosms on four occasions (July 15, Aug. 5, Sept 8. and Oct

174 20, Fig. S1). At the end of the experiment (Oct 23rd) we quantified total macrophyte biomass

175 in terms of above-ground dry weight (procedure: see above). This included both the original

176 inoculated species and a filamentous algae species that colonized the sediment surface of all

177 the mesocosms (see Table S1).

178 Ecosystem dynamics measurement using multiparameter sondes

179 We measured high-frequency ecosystem dynamics in the mesocosms from July 18th to Oct

180 23rd, 2015, using four autonomous multi parameter instruments (EXO2 modular sensor

181 platform [YSI-WTW], hereafter referred to as sondes). The sondes were placed approximately

182 at the center of the mesocosm $(\sim 0.5 \mathrm{~m}$ depth), away from the walls and outside of patches of

183 macrophytes. Additionally, we measured photosynthetically active radiation (PAR) in 15 min

184 intervals using a quantum sensor (Li-Cor) installed onsite to estimate surface light irradiance.

185 PAR and temperature data (Fig. S2) were used together with the dissolved oxygen data to

186 calculate metabolic rates (see Ecosystem Metabolism Modelling).

187 Sensors - The sondes were equipped with modular sensors that recorded the following ecosystem parameters at 15 minute intervals (see Table 1 for details): temperature, chlorophylla and phycocyanin (as proxies for phytoplankton biomass), dissolved oxygen, fluorescent

190 dissolved organic matter (hereafter fDOM) and specific conductivity (hereafter conductivity).

191 The sondes were equipped with an autonomous wiper that cleaned the sensor heads once every

192 hour. All sensors were thoroughly cleaned whenever the sondes were moved to another mesocosm (see Contrasts and sampling design). 
194 Calibration - Prior to the experiment, we performed a 48h cross-comparison trial where we

195 installed all the sondes in a single mesocosm, enabling us to correct for differences among

196 sensors and calibrate them against each other. During the cross-comparison trial we also

197 quantified chlorophyll-a concentration by analyzing water samples with high performance

198 liquid chromatography (HPLC, Jasco), and calibrated the optical sensors installed on the

199 sondes in accordance with the manufacturer's manual (YSI-WTW). Hence, we report

200 chlorophyll-a as $\mu \mathrm{g} * \mathrm{~L}^{-1}$, Phycocyanin and $\mathrm{fDOM}$ as raw fluorescence units. The oxygen

201 sensors were calibrated against water-saturated air.

202 Contrasts and sampling design - At the beginning of the experiment, all four sondes were 203 randomly assigned to two pairs of M+ and M- tanks. Because we only had four sondes 204 available, the four sondes were taken out of these tanks after 10 days, thoroughly cleaned, and 205 then introduced to the two remaining pairs, where they were left for another 10-day period (Fig.

206 1). Over the entire study we repeated this two-part cycle five times, yielding five distinct 207 periods in which all tanks were sampled (Fig. 2-4: t1-t5). On the third sampling period (t3) we 208 reduced the length of the measurement period to 7 days per set of tanks due to battery issues 209 with the Sondes. Between all transfers, we thoroughly cleaned the sondes by hosing down the 210 sondes and sensor bodies with a power washer before reinstalling them. We included the 211 distinct periods ( $\mathrm{t} 1-\mathrm{t} 5)$ resulting from the rotation scheme and each individual tank as a random 212 effect in all statistical models (see Statistical Analysis).

\section{Ecosystem metabolism estimation}

214 We used the temperature and oxygen measurements $\left(m g * \mathrm{~L}^{-1}\right)$ from the sondes and the PAR-

215 measurements from the light sensor to model whole ecosystem metabolic rates of each 216 mesocosm (for an overview of the abiotic conditions see Fig. S2). We used the 217 "streamMetabolizer" package (Appling et al., 2018) in the programming language R (R Core 
218 Team 2017) which applies inverse modelling to estimate daily rates of ecosystem gross

219 primary productivity (GPP), ecosystem respiration (ER) and gas exchange (K600) as g oxygen

$220 * \mathrm{~m}^{-2} *$ day $^{-1}$. For every modelled rate we calculated the ratio of GPP and R. Prior to modelling

221 we smoothed all input data with a 12-hour moving average window to facilitate model

222 convergence (A. Appling, personal communication) and for more conservative estimates.

223 Occasionally the model converged towards positive daily respiration rates (8 out of 312

224 estimates) and negative daily productivity rates (2 out of 312 estimates), which we omitted.

225 We used a Bayes-type model with pooled K600 for gas-exchange and lognormal priors $(\mathrm{K}=$

$2260-1)$. Because the dissolved oxygen time series reflects oxygen produced and consumed by all

227 organisms in the whole ecosystem, we assumed the model reflects the net effects of any

228 biomass changes throughout the experiment, for example, due to plant or epiphytic growth, or

229 biomass decay.

\section{$230 \quad$ DOC sampling}

231 For each pair of tanks within each measurement period (i.e. every 10 or 7 days: Table S2) we took a water sample for the analysis of DOC concentration and absorbance properties (Fig. S3).

Water samples were filtered through $47 \mathrm{~mm}$ ashed GF/Fs (6 hours at $450^{\circ} \mathrm{C}$ ), acidified with

$234 \mathrm{HCl} 2 \mathrm{M}$ and preserved at $4^{\circ} \mathrm{C}$ in the dark until analysis via high temperature catalytic oxidation

235 (TOC-VCS, Shimadzu), with a detection limit of $0.5 \mathrm{mg}^{*} \mathrm{~L}^{-1}( \pm 0.5)$. Specific ultraviolet absorbances (SUVA) were measured on the same samples from scans (1 nm intervals) on a Shimadzu UV1700 spectrophotometer, using $1 \mathrm{~cm}$ quartz cuvettes. We selected absorbance at $254 \mathrm{~nm}\left(\mathrm{SUVA}_{254}\right)$ as a proxy of aromaticity and reactivity of DOC (Weishaar et al., 2003). Furthermore, we measured SUVA350, which is an indicator for how much UVA radiation is

240 absorbed in the water (Fischer et al., 2015). We normalized the SUVA measurements by dividing the sample absorbances by the total DOC concentration (Hansen et al., 2016). Finally, 
we calculated spectral slope ratio (SSR) as the ratio of linear regressions of the log-transformed spectra of 275-295 nm and 350-400 nm (Helms et al., 2008; Hansen et al., 2016). SSR is a common proxy for DOC molecular weight, to which it should be inversely related. We were unable to analyze two DOC timepoints over the course of the experiment (Oct 2nd, and 17th) due to technical problems with the TOC analyzer.

\section{A model for competition between macrophytes and phytoplankton}

We used an existing model for competition between macrophytes and phytoplankton (Scheffer \& Carpenter, 2003) to explore how mesocosm phytoplankton dynamics might differ in the presence and absence of macrophytes. This model assumes standard features of macrophytephytoplankton interactions and implicitly accounts for competition for light and nutrients (Fig. a loss term following:

$$
\frac{d P}{d t}=r_{P} \frac{n}{n+h_{P}} \frac{1}{1+\alpha_{P} P} P-l_{P} P+\sigma \varepsilon_{P}(t)(\text { eq } 1 \mathrm{a})
$$

Phytoplankton grows with a maximum growth rate $r_{P}$ that is limited by nutrients $\mathrm{n}$ in a saturating function with half-saturation constant hp. Limitation of phytoplankton growth by macrophytes comes through nutrient availability given by eq2:

$$
n=\frac{N \operatorname{tot}}{1+q_{M} M+q_{P} P}(\mathrm{eq} 2)
$$

where Ntot is the total amount of nitrogen in the system and nutrients decrease in a nonlinear way depending on the biomass of macrophytes and phytoplankton. Parameters $q_{M}$ and $q_{P}$ determine the strength of the response in decreasing nutrients per biomass increase in macrophytes and phytoplankton, respectively. Phytoplankton growth is also limited by light due to self-shading scaled by $\alpha_{P}$ where $1 / \alpha_{P}$ is the biomass of phytoplankton that makes the 
maximum growth rate equal to half, whereas loss is determined by loss rate $l_{p}$, Macrophyte maximum growth rate $r_{M}$ is limited only due to competition for light (in contrast to phytoplankton which is also limited by nutrients). In that case, light limitation is driven by selfshading through parameter $a_{M}$ and due to shading by phytoplankton by parameter $b$. Loss is determined by loss rate $l_{M}$. In this simplified model formulation, we ignore some potentially important interactions for which we had no empirical data, including nutrient uptake by macrophytes from the sediment, and interactions between macrophytes and periphyton biomass over time.

We used model parameters such that both macrophytes and phytoplankton were equivalent in the rates of growth $\left(r_{P}=r_{M}=0.5\right)$, mortality $\left(l_{P}=l_{M=0.05}\right)$, and self-shading $\left(\alpha_{P}=\alpha_{M}=0.01\right)$. Instead, we modeled asymmetry between macrophytes and phytoplankton in terms of light and nutrient limitation. Phytoplankton growth was limited by nutrients $\left(h_{P}=0.2\right)$, through macrophytes having a stronger impact on retaining the available nutrients in the water column (Ntot) $\left(q_{M}=0.075\right.$ and $\left.q_{P}=0.005\right)$. Macrophytes became light limited by phytoplankton due to shading $(b=0.02)$. We set Ntot=3.2. This is a total nutrient level value for which the model can give rise to 2 alternative states, one state with both macrophytes and phytoplankton present $(\mathrm{M}+)$ and an alternative with phytoplankton but no macrophytes (M-). These two states resemble our experimental setup. We simulated model dynamics at these two contrasting states in the presence of environmental stochasticity $\varepsilon \mathrm{P}(\mathrm{t}), \varepsilon \mathrm{M}(\mathrm{t})$ (iid and different for macrophytes and phytoplankton) with strength $\sigma(=0.5)$. We produced 200 simulated sets of 1000 timepoints in length for each of the two states using the same sequence of stochastic

287 realizations for both states. In that way, differences in the recorded standard deviation and coefficient of variation were independent of the stochasticity and only due to the stability of the two states. The model was implemented in MATLAB R2016b (Mathworks) using Grind 


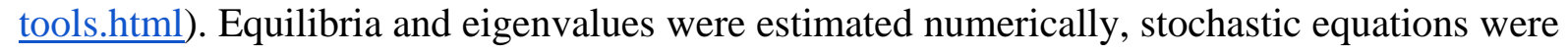

292 solved with Euler-Murayama integration using a 0.01 step.

\section{Statistical analysis}

294 Data treatment - Prior to the statistical analysis we removed incomplete days at the beginning and end of each measurement period (five time series: $11-\mathrm{t5}$ ). After this, each of the five time series had 864 data points ( 15 min interval = 96 data points per day = 9 days $)$ for $\mathrm{t} 1-3$ and 576 data points (= 6 days) for 44 and $\mathrm{t} 5$. In a second step, we identified residuals of the detrended data that were outside 2.5 times the interquartile range as outliers and removed them from the data set. Finally, we used sliding windows with a size of 96 timepoints (= 1 day) to calculate time series of mean and cv, resulting in 768 data points for $\mathrm{t} 1 \mathrm{-t} 3$ and 480 data points for $\mathrm{t} 4-\mathrm{t} 5$

301 (8 and 5 days, respectively).

302 Ecosystem dynamics - We analyzed time series of chlorophyll-a, phycocyanin, dissolved 303 oxygen and fDOM separately for each of the five measurement periods to account for any variation due to the sonde-switching. To test for effects of macrophytes on the mean and variance of each parameter we implemented a series of generalized additive models (GAM) using the R-package mgcv (Wood, 2004): one model per parameter (chlorophyll-a, Phycocyanin, fDOM, oxygen concentration, conductivity) per measurement period (t1-t5) per metric (mean or $\mathrm{CV}$ ), resulting in a total of 50 separate GAMs. Each model used data from all

309 eight tanks to test for differences in the mean or coefficient of variation (CV), with the presence or absence of macrophytes as the independent variable and tank and pair (see Fig. 1) as random

311 effects. All GAMs included a term that accounted for first order autocorrelation and used

312 penalized thin plate regression splines with automatic knot selection.

In addition to the GAMs we also calculated pairwise log response ratios (LRR) for macrophyte presence in all five periods for the high frequency measurements. To do so we 
315 divided vectors of mean and CV (coming either from the sliding window for the water

316 parameters or from the daily estimates of metabolism) for M+ by the corresponding vector of

317 M- for each given pair of tanks. We then calculated the natural logarithm for these ratios for

318 each measurement period and for each tank (for a summary of all response ratios see Fig. 6).

319 Ecosystem metabolism - To test for statistical differences in metabolic rates, we used the output

320 from the ecosystem metabolism models, which were 8 or 5 consecutive days for $\mathrm{t} 1$-t 3 , and t4-

321 t5, respectively (streamMetabolizer does not provide estimates for the final day in a time series). In a similar fashion as for the ecosystem dynamics, each model used data from all eight tanks within a measurement period to test for differences in GPP, ER or GPP:ER, using macrophyte presence as the independent variable and pair and tank as random effects. We calculated LRRs in the same way as described for the high frequency ecosystem dynamics. We used paired t-tests to test for differences in metabolism CV for each measurement period.

DOC - We used paired t-tests to test for differences in mean and CV of total DOC concentration, SUVA254 and SUVA350, and SSR between mesocosms with and without macrophytes. For each date (10 dates in total, see Table S2) we performed separate tests for all

330 four metrics ( $\mathrm{n}=8$ tanks). We performed t-tests with the stats $\mathrm{R}$-package (R Core Team 2017) and calculated pairwise LRRs for all DOC metrics (for a summary of all response ratios see 332 Fig. 6).

\section{Results}

\section{Macrophyte biomass and nutrients}

335 The overall biomass of the macrophyte community changed over the course of the experiment, decreasing in the M+treatment and increasing slightly in the M- treatment. At the end of the experiment substantially less Chara biomass was present in the $\mathrm{M}+$ mesocosms than at the 
beginning (from $165.1 \pm 21.65$ to $5.08 \pm 7.6$ g dry weight per mesocosm, mean \pm SD; Table

339 S1), whereas Myriophyllum biomass increased threefold from $2.84 \pm 0.54 \mathrm{~g}$ to $8.45 \pm 1.6 \mathrm{~g}$ dry

340 weight. In the M- treatment there was no Myriophyllum, but Chara biomass increased slightly

341 due to growth from the sediment (from 0 to $0.27 \pm 0.54 \mathrm{~g}$ dry weight per mesocosm, mean \pm 342 SD). In both treatments, filamentous algae grew over the course of the experiment to a final 343 biomass of $8.33 \pm 10.54 \mathrm{~g}$ dry weight $(\mathrm{M}+)$ and $3.21 \pm 5.46 \mathrm{~g}$ dry weight per mesocosm $(\mathrm{M}-)$, 344 mean \pm SD, respectively. Throughout the experiment we observed no differences in concentrations of phosphate or nitrogen between mesocosms with and without macrophytes

346 (Figure S1). The nutrients we supplied on July 4th were almost completely consumed by July 347 18th and were consistently low $\left(<2 \mu \mathrm{g} \mathrm{P} * \mathrm{~L}^{-1},<50 \mu \mathrm{g} \mathrm{N} * \mathrm{~L}^{-1}\right)$ over the entire experiment. 348 However, concentrations of both nutrients tended to increase towards the end of the 349 experiment, likely due to decomposition of plant material (e.g. Chara, Table S1).

\section{$350 \quad$ Ecosystem dynamics}

351 As expected, solar radiation and water temperature decreased strongly over the course of the experiment from July 18th to Oct 20th (Fig. S2). Several parameters differed between M+ and M- tanks over the course of the experiment, with the magnitude of the difference depending on period (Fig 2 and Fig. 6; for P-values see Table 2). As expected, mean phytoplankton biomass was significantly higher without macrophytes (M-) in three of the five periods $(\mathrm{t} 2, \mathrm{t} 4$, and $\mathrm{t} 5$;

356 Table 2), and, unexpectedly, the CV of phytoplankton biomass was higher in the tanks with macrophytes $(\mathrm{M}+)$ in three periods (t1, t2, and t5, Fig. 3). By comparison, mean phycocyanin was not significantly different between $\mathrm{M}+$ and $\mathrm{M}$ - (Fig. 2), but the $\mathrm{CV}$ of phycocyanin was significantly higher in the $\mathrm{M}+$ treatment during three periods (Fig. $3 ; \mathrm{t} 1, \mathrm{t} 2, \mathrm{t} 4$ ). In tanks with macrophytes $(M+)$, fDOM was higher in four periods (GAM, t2 - t5), and the CV was significantly lower in one period (GAM, t3). The mean concentration of dissolved oxygen was 
362 significantly higher in $\mathrm{M}+$, but only towards the end of the experiment (Fig. 3, t4 and t5). In

363 these two periods when irradiance was decreasing (Fig. S2), the tanks lacking macrophytes (M-

364 ) became undersaturated with dissolved oxygen indicating net heterotrophy. During the entire

365 experiment, there were no differences between $\mathrm{M}+$ and $\mathrm{M}$ - in the $\mathrm{CV}$ of dissolved oxygen.

366 Effect sizes of macrophyte presence on mean and variance of all parameters measured in high

367 frequency are summarized in Figure 6.

\section{Ecosystem metabolism}

369 We found weak and seasonally variable differences in mean ecosystem metabolism between mesocosms with and without macrophytes (Fig. 4). In three measurement periods mesocosms with macrophytes had significantly higher gross primary productivity (t1, t3, and t5). During t1, mesocosms with macrophytes also had higher respiration (GAM, main effect of macrophytes, $\mathrm{P}=0.001)$. In $\mathrm{t} 2$ there was a tendency for higher GPP:ER ratio in mesocosms without macrophytes (GAM, main effect of macrophytes, $\mathrm{P}=0.074)$, but in $\mathrm{t} 3$ and $\mathrm{t} 4$ we found the opposite pattern with significantly higher GPP:ER ratio in the presence of macrophytes (GAM, main effect of macrophytes, $\mathrm{P}<0.001$ and $\mathrm{P}=0.002$, respectively. Overall, GPP and ER decreased significantly over the course of the experiment, likely due to seasonal dynamics

378 (decreasing temperature and light, Fig. S2) but the GPP:ER ratio remained around one. Across

379 all measurement periods, both productivity and respiration increased with chlorophyll-a 380 biomass (slope in Fig. S4). However, for a given chlorophyll-a concentration, both metabolic rates were higher in the presence of macrophytes than in their absence (intercept in Fig. S4). Moreover, we found higher variance of metabolic rates when macrophytes were present (all ttests of metabolism CV significantly different - Fig 6). 
386 Total DOC concentration was not significantly different between M+ and M- mesocosms

387 (Table S2, Fig. S3). However, there were clear effects of macrophytes on chromophoric

388 (impacting light transparency) DOC components: SUVA 254 and SUVA 350 were often higher in 389 the presence of macrophytes (Table S2, Fig. S3), indicating that less UV light was able to

390 penetrate in these ecosystems. SSR diverged among treatments early in the experiment and

391 remained higher in the $-\mathrm{M}$ treatment for most of the season (Fig. S3), potentially indicating 392 dissolved substances of lower molecular weight in the absence of macrophytes (e.g. sugars or 393 amino acids). We also found higher variance in all metrics of DOC composition in the presence 394 of macrophytes (Fig 6).

396 Simulated interactions between macrophytes and phytoplankton

397 Our simulation model produced results parallel to those observed in the mesocosms. Under 398 identical nutrient levels, phytoplankton biomass was on average lower in the presence of macrophytes, but also varied more strongly around the mean (i.e. lower mean and higher CV under M-). This was also reflected in the stability regimes measured as the dominant eigenvalue

401 lambda, which was higher in the absence and lower in the presence of macrophytes (Fig. 5,

402 panel B). These results emerged solely from differences in the relative effects of macrophytes 403 vs. phytoplankton on nutrient vs. light limitation and illustrate that differential competition for 404 these resources can impact both mean and variance in phytoplankton biomass.

\section{Discussion}

406 Over the course of the mesocosm experiment macrophytes affected a wide range of ecosystem 407 parameters. Most notably, from those measured at high frequency, chlorophyll-a fluorescence 
408 (i.e. phytoplankton biomass) was significantly lower in the presence of macrophytes. Our high-

409 resolution measurements also revealed some unexpected variance patterns of phytoplankton

410 and DOC components in the presence of macrophytes. While the former may be explained by

411 resource competition between macrophytes and phytoplankton, as indicated by our competition

412 simulation, the mechanisms behind elevated DOC variability are currently speculative. Below

413 we discuss the implications of our joint findings from the high-resolution time series and the

414 simulation model, as well as the outcomes of the ecosystem metabolism models. Overall, our

415 findings indicate that some macrophyte effects on ecosystem parameters are of more limited

416 duration (e.g. phytoplankton was decreased only temporarily and most strongly in t2), whereas

417 others remain stable across the season (e.g. fDOM was consistently higher from t2 onwards).

418 As expected from existing theoretical and experimental work, and confirming our first

419 hypothesis, we observed higher phytoplankton biomass in the absence of macrophytes

420 (Scheffer et al., 1993; Blindow et al., 1998). This is in agreement with a large body of previous

work that documents the outcome of competition between macrophytes and phytoplankton for dissolved nutrients and light (Sand-Jensen \& Borum, 1991; Scheffer et al., 1993; Faafeng \& Mjelde, 1998; van Nes, Rip \& Scheffer, 2007). The ability of macrophytes to keep phytoplankton biomass low is also known to be important in maintaining a clear water state in response to nutrient additions (Scheffer et al., 1993; Ibelings et al., 2007). However, a finding we did not expect based on existing theory was the higher variability of phytoplankton biomass in the presence of macrophytes, a phenomenon that has not been previously reported. One mechanism for higher variability of phytoplankton biomass could be that the ongoing photosynthesis, growth, and decay of macrophytes increases the short-term variability of nutrient and carbon availability, and that phytoplankton respond more rapidly to these changes in nutrient concentrations than macrophytes themselves (Setaro \& Melack, 1984; Mitchell, 1989; Eichel et al., 2014). Importantly, however, the much larger reservoir of macrophytes 
biomass can repeatedly suppress these rapid increases in phytoplankton growth. Rooted macrophytes build up biomass over time and can also store nutrients (Faafeng \& Mjelde, 1998; Søndergaard \& Moss, 1998; Yamamichi et al., 2018), and thus probably prevented a high mean level of phytoplankton biomass and repeatedly suppressed multiple bouts of phytoplankton growth.

We implemented a model to explore how competitive interactions between macrophytes and phytoplankton might affect the mean vs. the variance of phytoplankton biomass. Specifically, we modelled competitive interactions such that macrophytes limit nutrient availability and phytoplankton limit light availability (Scheffer and Carpenter (2003)). This model reproduced the same contrast in phytoplankton biomass that we observed in the mesocosms: lower mean phytoplankton biomass but higher variance $(\mathrm{CV})$ in the presence of macrophytes. Thus, the model predicted that a phytoplankton-dominated state would be more stable than a macrophyte-dominated state under the same nutrient loading condition. At first sight, this result might appear counterintuitive as a macrophyte-dominated state is expected to be more stable to the unfavorable phytoplankton-dominated state. The biological explanation may be that when macrophytes and phytoplankton are competing for nutrients (and light),

449 variation arising from the depletion of these resources is larger than with just one consumer (i.e. only phytoplankton in M-). However, whether variability is always expected to be higher in a macrophyte dominated than in a phytoplankton-dominated state, or under what conditions, would require more empirical work to validate. The model shows that this is the case considering only one aspect of macrophyte-phytoplankton interactions (i.e. competition), which qualitatively matched with the high-resolution algal biomass data we collected. However, macrophytes can affect other compartments of the ecosystem (e.g. sediment, epiphytes, DOC) that are not considered in our model. Macrophytes can produce allelochemicals like polyphenols and fatty acids (Korner \& Nicklisch, 2002; Nakai et al., 2012) 
that inhibit phytoplankton production (Hilt \& Gross, 2008; Nakai et al., 2012), can modify the

459 light environments via the production of DOC (Catalán et al., 2014; Reitsema et al., 2018),

460 which could potentially influence the variance of phytoplankton biomass. This may be

461 especially the case for Myriophyllum, which is known to produce large amounts of 462 allelochemicals (Hilt \& Gross, 2008; Nakai et al., 2012) and also was the dominant plant in the 463 mesocosms with macrophytes. Nevertheless, our study does illustrate that high resolution 464 monitoring of ecosystem conditions (Mandal et al., 2019), might provide new insights into the 465 underlying mechanisms whereby macrophytes (or other foundation species) can affect ecosystem dynamics in general, and the relationships between mean and variance of ecosystem responses in particular.

In line with macrophytes being efficient primary producers in shallow lakes (Kaenel et al., 2000), we confirmed our second hypothesis that mesocosm ecosystems with macrophytes had higher metabolic rates than those without macrophytes. Differences in productivity were most pronounced in July, where mesocosms with macrophytes were significantly more productive than macrophyte free mesocosms ( $\mathrm{t} 1)$. However, this difference disappeared during 473 the phytoplankton bloom in the second measurement period (t2). This suggests that at 474 intermediate concentrations, phytoplankton can increase productivity of aquatic ecosystems 475 and match rates of primary production of macrophytes. Yet for any given chlorophyll-a biomass we measured, metabolic rates were higher when macrophytes were also present. This 477 indicates that even at relatively low density, macrophytes (Myriophyllum, Chara and 478 filamentous algae) can produce a significant metabolic signal. Higher productivity of 479 ecosystems with macrophytes was also reflected in GPP:ER ratio, which is on average slightly 480 higher for those mesocosms in t3 and t4 (Sep 5th - Oct 9th). During t2 (Aug 7th - Aug 27th) 481 there was a tendency for higher GPP:ER in mesocosms without macrophytes, probably due to 482 very high phytoplankton biomass. Towards the second half of the experiment, the growth of 
filamentous algae may have also contributed to higher rates of whole ecosystem productivity in $+\mathrm{M}$ tanks, where filamentous algae biomass was higher $(8.33 \pm 10.54 \mathrm{~g}$ dry weight, mean \pm $\mathrm{SD})$ than in the $-\mathrm{M}$ tanks $(3.21 \pm 5.46 \mathrm{~g}$ dry weight, mean $\pm \mathrm{SD})$. Overall, these findings suggest that macrophytes, regardless of their growth form, might make shallow lake ecosystems more productive across the seasonal succession of ecosystem metabolism (Madsen \& Adams, 1988; Blindow et al., 2006; Brothers et al., 2013). These dynamics require additional investigation, especially in the context of successive phytoplankton blooms and their effects on the macrophyte community, but also in the context of rising temperatures and eutrophication. their effects on the concentration and composition of dissolved organic matter. From the beginning of $\mathrm{t} 2$ (August 8 th) to the end of the experiment, fDOM measurements in mesocosms with macrophytes were nearly twice as high as in mesocosms without macrophytes. Higher mean, but also lower variance of DOM was expected, because especially Myriophyllum, which was the dominant plant in the $+\mathrm{M}$ mesocosms, is known to produce allelochemicals to inhibit algae growth that are broken down only slowly (Hilt \& Gross, 2008; Nakai et al., 2012). However, total DOC concentrations were similar in both treatments, suggesting that not all 499 components of the DOM-pool are affected the same way by macrophytes (Catalán et al., 2014; Reitsema et al., 2018). Moreover, measurements from the scanning spectrophotometer showed consistently lower SSRs, indicating the presence of DOC compounds with higher molecular 502 weight. The buildup and decay of macrophyte detritus could explain the low SSR ratios at 503 similar total DOC levels, particularly since much of the initial Chara biomass contributed to 504 decomposition rather than taking root, and/or grew but then decayed over the course of the experiment. However, Myriophyllum biomass also increased substantially, and could have added high MW compounds into the mesocosms. It is also possible that production rates of

507 DOC were similar in M+ and M- treatments (as the total DOC was similar), but that material 
508 originating from macrophytes has a higher MW, and is more difficult to break down by bacteria

509 (Bolan et al., 2011; Reitsema et al., 2018). Overall, changes in DOC composition and variance

510 might reflect differences in the balance of production and decomposition rates of different

511 photosynthetic compounds, such as low MW sugars that are a byproduct of recent

512 photosynthetic activity (Carpenter \& Lodge, 1986; Bolan et al., 2011; Reitsema et al., 2018).

513 However, more work needs to be done to understand the specific mechanisms behind such

514 patterns, e.g. biomass production and decomposition or the production of secondary 515 metabolites.

516 Using a common macrophyte assemblage, our experiment shows that communities of 517 submerged plants can affect the mean and variance of a wide range of biotic and abiotic 518 ecosystem properties and processes over a relatively short amount of time (Figure 6). Some of 519 the effects we found on mean values, such as macrophytes decreasing phytoplankton biomass 520 and increasing fDOM are not particularly surprising nor are they novel. However, the elevated variability of both phytoplankton pigments in the presence of macrophytes was unexpected, and potentially linked to competitive interactions. Across all our ecosystem metrics, we found

523 that changes in CV covaried negatively with changes in the mean, or that CV increased despite 524 no effect on the mean. Such results, show the importance of considering the variance of 525 ecological dynamics, which is increasingly recognized as an important aspect of ecosystem dynamics (Carpenter, 1988; Benedetti-Cecchi, 2003) and is used in a wide array of applications, e.g. ecological forecasting (Petchey et al., 2015; Pennekamp et al., 2019), early warning signals for critical transitions (Scheffer et al., 2009; Carpenter et al., 2011), and ecological modelling (Bartell et al., 1988; Cottingham \& Carpenter, 1998). Furthermore, our high frequency measurements can begin to reveal and quantify characteristic differences in

531 timescales of ecosystem change, such as the high variability in phytoplankton communities vs.

532 the relative stability of DOM and oxygen concentration throughout the season. Future 
experiments targeting shallow lake ecosystems should also encompass measurements in high

534 resolution, e.g. to detect the potential outcome of interactions among different trophic levels (e.g. between macrophytes, zooplankton and fish) or quantify the response to perturbations (e.g. nutrients or temperature). Our study highlights how complex and temporally variable interactions around foundation species can be and underscores the need for further research that investigates biotic and abiotic components of these networks of interactions in detail.

\section{Acknowledgements}

540 We thank Gilles Antoniazza, Emil Birnstiel, Laetitia Catalano, Daniel Steiner, Jaime M.

541 Anaya-Rojas, and Marek Svitok for major contributions to mesocosm set-up, maintenance, and sampling. Patrick Kathriner, and Beat Kienholz provided lab facilities and infrastructure support. MDL was funded by the center for Adaptation to a changing Environment (ACE) at

544 ETH Zürich and by the department of Aquatic Ecology at Eawag. The Eawag Directorate 545 provided financial support for RJB and MDL.

\section{Author contributions}

547 MDL, BM, and RJB designed the study. MDL and RJB implemented and maintained the experiment and collected the data. MDL, VD and BM analyzed the data. VD implemented the simulation model. All authors made substantial contributions to the manuscript.

\section{Data Availability Statement}

551 A copy of the (cross) calibrated data is accessible at the Dryad open-access repository:

552 https://doi.org/10.5061/dryad.18931zcvt (Lürig et al. 2020), together with instructions on how 553 to reproduce all shown results. 


\section{Conflict of interest}

555 The authors declare no conflict of interests.

556 References

557 Appling A.P., Hall R.O. Jr., Yackulic C.B. \& Arroita M. (2018). Overcoming Equifinality:

558 Leveraging Long Time Series for Stream Metabolism Estimation. Journal of

559 Geophysical Research: Biogeosciences 123, 624-645.

560

https://doi.org/10.1002/2017JG004140

561

Bartell S.M., Brenkert A.L., O’Neill R.V. \& Gardner R.H. (1988). Temporal Variation in Regulation of Production in a Pelagic Food Web Model. In: Complex Interactions in Lake Communities. (Ed. S.R. Carpenter), pp. 101-118. Springer New York, New York, NY.

Benedetti-Cecchi L. (2003). The Importance of the Variance around the Mean Effect Size of Ecological Processes. Ecology 84, 2335-2346

Blindow I., Hargeby A. \& Andersson G. (1998). Alternative Stable States in Shallow Lakes: What Causes a Shift? In: The Structuring Role of Submerged Macrophytes in Lakes. Ecological Studies, (Eds E. Jeppesen, M. Søndergaard, M. Søndergaard \& K. Christoffersen), pp. 353-360. Springer New York.

Blindow I., Hargeby A., Meyercordt J. \& Schubert H. (2006). Primary production in two shallow lakes with contrasting plant form dominance: A paradox of enrichment? Limnology and oceanography 51, 2711-2721. https://doi.org/10.4319/1o.2006.51.6.2711

Bolan N.S., Adriano D.C., Kunhikrishnan A., James T., McDowell R. \& Senesi N. (2011). 
578 Brothers S.M., Hilt S., Meyer S. \& Koehler J. (2013). Plant community structure determines primary productivity in shallow, eutrophic lakes. Freshwater biology 58, 2264-2276. https://doi.org/10.1111/fwb.12207

Carpenter S.R. (1988). Transmission of Variance through Lake Food Webs. In: Complex Interactions in Lake Communities. (Ed. S.R. Carpenter), pp. 119-135. Springer New York, New York, NY.

Carpenter S.R., Cole J.J., Pace M.L., Batt R., Brock W.A., Cline T., et al. (2011). Early warnings of regime shifts: a whole-ecosystem experiment. Science 332, 1079-1082. https://doi.org/10.1126/science.1203672

Carpenter S.R. \& Lodge D.M. (1986). Effects of submersed macrophytes on ecosystem processes. Aquatic botany 26, 341-370. https://doi.org/10.1016/0304-3770(86)90031-8

Catalán N., Obrador B. \& Pretus J.L. (2014). Ecosystem processes drive dissolved organic matter quality in a highly dynamic water body. Hydrobiologia 728, 111-124. https://doi.org/10.1007/s10750-014-1811-y

Cottingham K.L. \& Carpenter S.R. (1998). Population, Community, and Ecosystem Variates as Ecological Indicators: Phytoplankton Responses to Whole-Lake Enrichment. Ecological applications: a publication of the Ecological Society of America 8, 508-530. https://doi.org/10.2307/2641090

Dayton P.K. (1972). Toward an understanding of community resilience and the potential effects of enrichments to the benthos at McMurdo Sound, Antarctica. In: Proceedings of

600 Eichel K.A., Macrae M.L., Hall R.I., Fishback L. \& Wolfe B.B. (2014). Nutrient Uptake and 
Subarctic Pond to Experimental Nutrient Enrichment in Microcosms. Arctic, antarctic, and alpine research 46, 191-205. https://doi.org/10.1657/1938-4246-46.1.191

604 Ellison A.M., Bank M.S., Clinton B.D., Colburn E.A., Elliott K., Ford C.R., et al. (2005).

605 Loss of foundation species: consequences for the structure and dynamics of forested

606 ecosystems. Frontiers in ecology and the environment 3, 479-486.

607 https://doi.org/10.1890/1540-9295(2005)003[0479:LOFSCF]2.0.CO;2

608 Faafeng B.A. \& Mjelde M. (1998). Clear and Turbid Water in Shallow Norwegian Lakes

609 Related to Submerged Vegetation. In: The Structuring Role of Submerged Macrophytes

610 in Lakes. Ecological Studies, (Eds E. Jeppesen, M. Søndergaard, M. Søndergaard \& K.

611 Christoffersen), pp. 361-368. Springer New York.

612 Findlay S. \& Sinsabaugh R.L. (2003). Aquatic Ecosystems: Interactivity of Dissolved

613 Organic Matter. (Ed. F. Sinsabaugh), Academic Press.

614 Fiskal A., Deng L., Michel A., Eickenbusch P., Han X., Lagostina L., et al. (2019). Effects of

615 eutrophication on sedimentary organic carbon cycling in five temperate lakes

616 Gross E.M. (2003). Allelopathy of Aquatic Autotrophs. Critical reviews in plant sciences 22,

617 313-339. https://doi.org/10.1080/713610859

618 Hansen A.M., Kraus T.E.C., Pellerin B.A., Fleck J.A., Downing B.D. \& Bergamaschi B.A. 619 (2016). Optical properties of dissolved organic matter (DOM): Effects of biological and 620 photolytic degradation: DOM optical properties following degradation. Limnology and oceanography 61, 1015-1032. https://doi.org/10.1002/lno.10270

622 Helms J.R., Stubbins A., Ritchie J.D., Minor E.C., Kieber D.J. \& Mopper K. (2008).

623 Absorption spectral slopes and slope ratios as indicators of molecular weight, source, and photobleaching of chromophoric dissolved organic matter. Limnology and oceanography 53, 955-969. https://doi.org/10.4319/lo.2008.53.3.0955

626 Hillebrand H., Langenheder S., Lebret K., Lindström E., Östman Ö. \& Striebel M. (2018). 

Decomposing multiple dimensions of stability in global change experiments. Ecology letters 21, 21-30. https://doi.org/10.1111/ele.12867

Hilt S. \& Gross E.M. (2008). Can allelopathically active submerged macrophytes stabilise clear-water states in shallow lakes? Basic and applied ecology 9, 422-432. https://doi.org/10.1016/j.baae.2007.04.003

Huss A.A. \& Wehr J.D. (2004). Strong indirect effects of a submersed aquatic macrophyte, Vallisneria americana, on bacterioplankton densities in a mesotrophic lake. Microbial ecology 47, 305-315. https://doi.org/10.1007/s00248-003-1034-7

Iacarella J.C., Barrow J.L., Giani A., Beisner B.E. \& Gregory-Eaves I. (2018). Shifts in algal

Ibelings B.W., Portielje R., Lammens E.H.R.R., Noordhuis R., van den Berg M.S., Joosse W., et al. (2007). Resilience of Alternative Stable States during the Recovery of Shallow https://doi.org/10.1007/s10021-006-9009-4

Jeppesen E., Peder Jensen J., Søndergaard M., Lauridsen T., Junge Pedersen L. \& Jensen L. (1997). Top-down control in freshwater lakes: the role of nutrient state, submerged

Kaenel B.R., Buehrer H. \& Uehlinger U. (2000). Effects of aquatic plant management on stream metabolism and oxygen balance in streams. Freshwater biology 45, 85-95. https://doi.org/10.1046/j.1365-2427.2000.00618.x stable states in ecosystems? Functional ecology 30, 88-97. https://doi.org/10.1111/1365- 
653 Kellerman A.M., Kothawala D.N., Dittmar T. \& Tranvik L.J. (2015). Persistence of dissolved 654 organic matter in lakes related to its molecular characteristics. Nature geoscience $\mathbf{8}, 454$. https://doi.org/10.1038/ngeo2440

Korner S. \& Nicklisch A. (2002). Allelopathic growth inhibition of selected phytoplankton species by submerged macrophytes. Journal of phycology 38, 862-871.

658 https://doi.org/10.1046/j.1529-8817.2002.t01-1-02001.x

659

Lürig, M.D., Best, R. J., Dakos, V, Matthews, B. (2020). Data from: Submerged macrophytes

660

661 affect the temporal variability of aquatic ecosystems. Dryad Digital Repository

662 https://doi.org/10.5061/dryad.18931zcvt

Madsen J.D. \& Adams M.S. (1988). The seasonal biomass and productivity of submerged 663 macrophytes in a polluted Wisconsin stream. Freshwater biology 20, 41-50.

664 https://doi.org/10.1111/j.1365-2427.1988.tb01715.x

665

Mandal S., Smith S.L., Priyadarshi A. \& Yamazaki H. (2019). Micro-Scale Variability 666 Impacts the Outcome of Competition Between Different Modeled Size Classes of

668 Phytoplankton. Frontiers in Marine Science 6, 259.

669 https://doi.org/10.3389/fmars.2019.00259

Mitchell D.S. \& Rogers K.H. (1985). Seasonality/aseasonality of aquatic macrophytes in 670 Southern Hemisphere inland waters. Hydrobiologia 125, 137-150. https://doi.org/10.1007/BF00045931

Mitchell S.F. (1989). Primary production in a shallow eutrophic lake dominated alternately by phytoplankton and by submerged macrophytes. Aquatic botany 33, 101-110. https://doi.org/10.1016/0304-3770(89)90023-5 fatty acids responsible for anti-cyanobacterial allelopathic effects of submerged 
677

678

679

680

681

682

683

684

685

686

687

688

689

690

691

692

693

694

695

696

697

698

699

700

701

macrophyte Myriophyllum spicatum. Water science and technology: a journal of the International Association on Water Pollution Research 66, 993-999. https://doi.org/10.2166/wst.2012.272

van Nes E.H., Rip W.J. \& Scheffer M. (2007). A theory for cyclic shifts between alternative states in shallow lakes. Ecosystems 10, 17-27. https://doi.org/10.1007/s10021-0060176-0

Nielsen A., Liboriussen L., Trolle D., Landkildehus F., Søndergaard M., Lauridsen T.L., et al. (2013). Daily net ecosystem production in lakes predicted from midday dissolved oxygen saturation: analysis of a five-year high frequency dataset from 24 mesocosms with contrasting trophic states and temperatures: Predicting lake net ecosystem production. Limnology and oceanography, methods / ASLO 11, 202-212. https://doi.org/10.4319/lom.2013.11.202

Pennekamp F., Iles A.C., Garland J., Brennan G., Brose U., Gaedke U., et al. (2019). The intrinsic predictability of ecological time series and its potential to guide forecasting. Ecological monographs 89, e01359. https://doi.org/10.1002/ecm.1359

Petchey O.L., Pontarp M., Massie T.M., Kéfi S., Ozgul A., Weilenmann M., et al. (2015). The ecological forecast horizon, and examples of its uses and determinants. Ecology letters 18, 597-611. https://doi.org/10.1111/ele.12443

Reitsema R.E., Meire P. \& Schoelynck J. (2018). The Future of Freshwater Macrophytes in a Changing World: Dissolved Organic Carbon Quantity and Quality and Its Interactions With Macrophytes. Frontiers in plant science 9, 629. https://doi.org/10.3389/fpls.2018.00629

Retamal L., Vincent W.F., Martineau C. \& Osburn C.L. (2007). Comparison of the optical properties of dissolved organic matter in two river-influenced coastal regions of the Canadian Arctic. Estuarine, coastal and shelf science 72, 261-272. 
https://doi.org/10.1016/j.ecss.2006.10.022

703

704

705

706

707

708

709

710

711

712

713

714

715

716

717

718

719

720

721

722

723

724

725

726

Sand-Jensen K. \& Borum J. (1991). Interactions among phytoplankton, periphyton, and macrophytes in temperate freshwaters and estuaries. Aquatic botany 41, 137-175. https://doi.org/10.1016/0304-3770(91)90042-4

Scheffer M., Bascompte J., Brock W.A., Brovkin V., Carpenter S.R., Dakos V., et al. (2009). Early-warning signals for critical transitions. Nature 461, 53-59. https://doi.org/10.1038/nature08227

Scheffer M. \& Carpenter S.R. (2003). Catastrophic regime shifts in ecosystems: linking theory to observation. Trends in ecology \& evolution 18, 648-656. https://doi.org/10.1016/j.tree.2003.09.002

Scheffer M., Hosper S.H., Meijer M.L., Moss B. \& Jeppesen E. (1993). Alternative equilibria in shallow lakes. Trends in ecology \& evolution 8, 275-279. https://doi.org/10.1016/0169-5347(93)90254-M

Scheffer M., Szabo S., Gragnani A., Van Nes E.H., Rinaldi S., Kautsky N., et al. (2003). Floating plant dominance as a stable state. Proceedings of the National Academy of Sciences of the United States of America 100, 4040-4045. https://doi.org/10.1073/pnas.0737918100

Setaro F.V. \& Melack J.M. (1984). Responses of phytoplankton to experimental nutrient enrichment in an Amazon floodplain lake1: Amazon lake nutrient limitation. Limnology and oceanography 29, 972-984. https://doi.org/10.4319/lo.1984.29.5.0972

Søndergaard M. \& Moss B. (1998). Impact of Submerged Macrophytes on Phytoplankton in Shallow Freshwater Lakes. In: The Structuring Role of Submerged Macrophytes in Lakes. (Eds E. Jeppesen, M. Søndergaard, M. Søndergaard \& K. Christoffersen), pp. 115-132. Springer New York, New York, NY.

Spears B.M., Futter M.N., Jeppesen E., Huser B.J., Ives S., Davidson T.A., et al. (2017). 
Ecological resilience in lakes and the conjunction fallacy. Nature ecology \& evolution $\mathbf{1}$, 1616-1624. https://doi.org/10.1038/s41559-017-0333-1

Van den Berg M.S., Coops H., Meijer M.-L., Scheffer M. \& Simons J. (1998). Clear Water Associated with a Dense Chara Vegetation in the Shallow and Turbid Lake Veluwemeer, The Netherlands. In: The Structuring Role of Submerged Macrophytes in Lakes. (Eds E. Jeppesen, M. Søndergaard, M. Søndergaard \& K. Christoffersen), pp. 339-352. Springer New York, New York, NY.

Vasseur D.A., DeLong J.P., Gilbert B., Greig H.S., Harley C.D.G., McCann K.S., et al. (2014). Increased temperature variation poses a greater risk to species than climate warming. Proceedings. Biological sciences / The Royal Society 281, 20132612. https://doi.org/10.1098/rspb.2013.2612

Weishaar J.L., Aiken G.R., Bergamaschi B.A., Fram M.S., Fujii R. \& Mopper K. (2003). Evaluation of Specific Ultraviolet Absorbance as an Indicator of the Chemical Composition and Reactivity of Dissolved Organic Carbon. Environmental science \& technology 37, 4702-4708. https://doi.org/10.1021/es030360x

Wetzel R.G. (1964). A Comparative Study of the Primary Production of Higher Aquatic Plants, Periphyton, and Phytoplankton in a Large, Shallow Lake. Internationale Revue der gesamten Hydrobiologie und Hydrographie 49, 1-61.

Wetzel R.G. \& Søndergaard M. (1998). Role of Submerged Macrophytes for the Microbial Community and Dynamics of Dissolved Organic Carbon in Aquatic Ecosystems. In: The Structuring Role of Submerged Macrophytes in Lakes. (Eds E. Jeppesen, M. New York, NY.

Wood S.N. (2004). Stable and efficient multiple smoothing parameter estimation for 

generalized additive models. Journal of the American Statistical Association 99, 673686

754 Yamamichi M., Kazama T., Tokita K., Katano I., Doi H., Yoshida T., et al. (2018). A shady 755 285, 20181067. https://doi.org/10.1098/rspb.2018.1067

757 Żbikowski J., Simčič T., Pajk F., Poznańska-Kakareko M., Kakareko T. \& Kobak J. (2019).

758 Respiration rates in shallow lakes of different types: contribution of benthic

759 microorganisms, macrophytes, plankton and macrozoobenthos. Hydrobiologia 828, $117-$

760 136. https://doi.org/10.1007/s10750-018-3807-5

761 Zelnik Y.R., Arnoldi J.-F. \& Loreau M. (2018). The Impact of Spatial and Temporal

762 Dimensions of Disturbances on Ecosystem Stability. Frontiers in ecology and evolution 6, 224. https://doi.org/10.3389/fevo.2018.00224 


\section{Figure captions}

767 1. A: Scheme of experimental procedure. Because we were limited to four sondes, we could 768 only measure two tank pairs of macrophyte $(\mathrm{M}+) /$ no macrophyte $(\mathrm{M}-)$ contrasts. To measure 769 all eight tanks, we followed a rotation scheme in which every tank was measured for 10 770 consecutive days before the sondes were moved to another tank (for details refer to Methods section). B: Picture of experimental site showing the set up mesocosms (1000L). C: Chara tomentosa (Photo credit: Gustav Johansson). D: Myriophyllum spicatum (Photo credit: Alison

773 Fox).

774 2. Sliding window results from high frequency measurements of chlorophyll-a and 775 Phycocyanin over time (days 2-9 in each of five consecutive sampling periods). Lines show 776 Mean \pm SE $(n=8$ tanks), asterisks indicate significant differences $(\mathrm{p}<=0.05)$, dots indicate marginal significance $(\mathrm{p}<=0.1)$. One GAM was used per period, including tank and the pair it was in (see Fig.1) as random effects. Here the sliding window time series of the Mean from both blocks are shown pooled for better illustration. Because the sliding window had a width

780 of one day, only aggregate days 2-9 for each measurement are shown.

781 3. Sliding window results from high frequency measurements of fDOM and dissolved oxygen

782 over time (days 2-9 in each of five consecutive sampling periods). Lines show Mean \pm SE ( $n$

$783=8$ tanks $)$, asterisks indicate significant differences $(\mathrm{p}<=0.05)$. One GAM was used per period,

784 including tank and the pair it was in (see Fig.1) as random effects. Here the sliding window

785 time series of the Mean from both blocks are shown pooled for better illustration. Because the 786 sliding window had a width of one day, only aggregate days 2-9 for each measurement are 787 shown. 
4. Ecosystem gross primary productivity (GPP), ecosystem respiration (ER) and GPP:ER, calculated from high frequency measurements of dissolved oxygen concentration $\left(\mathrm{g}^{*} \mathrm{~m}^{-2} *\right.$ day $\left.^{-1}\right)$, temperature, light, and air pressure. Shown are Mean \pm SE $(n=8$ tanks), asterisks indicate significant differences $(\mathrm{P}<0.05)$, dots indicate marginal significance $(\mathrm{P}<0.1)$. One GAM was used per period, including both consecutive blocks as random variables. Here the time series of metabolic rates from both blocks are shown pooled for better illustration. The modelling procedure requires full days to be included, but because of the model parameterization to start each day 1 hour before sunrise, the last day is incomplete and thus cannot be modeled. Hence, only aggregate days 1-8 are shown.

5. A simple model of competition for light and nutrients between macrophytes and phytoplankton (for details see Supplement). A: Schematic of interactions between macrophytes (M) and phytoplankton (P). Macrophytes consume nutrients, which has a negative indirect effect on phytoplankton. If phytoplankton biomass becomes too high, it reduces light levels such that there is a negative indirect effect on macrophytes. Thus, macrophytes are more

802 strongly limited by light, and phytoplankton by nutrients. B: Zero-growth curves of 803 macrophytes (green line) and phytoplankton (blue line). Black points mark the 2 alternative stable equilibria of either a macrophyte-and-phytoplankton state or an only-phytoplankton state. Although these two states exist for the same level of nutrients in the water, their stability (measured as the dominant eigenvalue lambda) differs: the only-phytoplankton is more stable

807 than the macrophyte-and-phytoplankton state. C: Simulated time series of phytoplankton 808 biomass in the presence (green) and in the absence (blue - note second y-axis) of macrophytes 809 for the same level of nutrients in the water. D: Coefficient of variation of phytoplankton 810 biomass estimated from 200 simulated sets. 
812 6. Average log response ratios (LRR) for macrophyte presence on mean and CV. Effect sizes

813 were calculated differently for each data type: high frequency $(\bullet)$, metabolism $(\boldsymbol{\Delta})$, or DOC

814 point measurements ( $\mathbf{\square})$ - for details refer to the methods section. Each point shows the average

815 (mean \pm se) macrophyte LRR across all tank pairs (N=4, Fig. 1) and in all measurement periods

816 (t1-t5, except for the DOC point measurements, where all 10 measurements were used to

817 calculate LRR for mean and CV). 
818 Figure S1 - Point measurements of dissolved nutrients $($ top $=$ phosphate, bottom $=$ nitrite +

819 nitrate). Throughout the experiment, on all four timepoints, there were no differences in 820 dissolved nutrient concentrations between mesocosms with and without macrophytes. We only 821 added nutrients at the beginning of the experiment; increasing nutrient concentrations therefore 822 underlie natural dynamics (e.g. increase due to rain and decomposition, decrease due to uptake 823 by plants).

824 Figure S2 - Abiotic conditions during experiment: Temperature was measured inside each 825 mesocosm with a sensor that was installed on the sondes (Table 2: no significant difference 826 among tanks). PAR was measured outside the mesocosms with a sensor (Li-Cor) that was 827 installed at the center of the side at water level height.

828 Figure S3 - Point measurements of different DOC components: total DOC, specific UV absorbance (SUVA: smaller values $=$ higher UV transmission) at 254 and $350 \mathrm{~nm}$, and the ratio

830 of spectral slopes (SSR; smaller values = higher molecular weight) at 275-295 and 350-400

$831 \mathrm{~nm}$. We used separate t-tests to test for differences in DOC components at each date (n per 832 treatment level $=4)$. Significant differences $(\mathrm{P}<0.05)$ are indicated by asterisks, marginal significance $(\mathrm{P}<0.1)$ is indicated by dots. All p-values are reported in table $\mathrm{S} 2$.

834 Figure S4 - Metabolic rates as a function of Chlorophyll A concentration (top = ecosystem 835 productivity [GPP], bottom = ecosystem respiration [ER]). Different symbols indicate the

836 different measurement periods (t1-t5). Overall, metabolic rates are determined by chlorophyll 837 biomass (slope of linear regression), but when macrophytes are present, metabolic rates are 838 higher (intercept of linear regression). 
840 Tables

841 1. Parameters measured in high frequency using autonomous sondes. Prior to the experiment

842 we performed a cross-comparison trial with all four sondes, after which we corrected all sensors

843 for relative differences among them (i.e., "cross" = cross calibration = calibrated against each

844 other). Chlorophyll-a sensors were additionally calibrated with samples taken during this trial

845 that were analyzed for their chlorophyll-a content with high pressure liquid chromatography

846 (HPLC). Oxygen sensors were calibrated against water-saturated air. (*fDOM-sensors measure

847 emission at $365 \pm 5$ and excitation at $480 \pm 40 \mathrm{~nm}$. **For metabolism modelling, concentration

$848 \quad\left[\mathrm{mg}\right.$ oxygen $\left.* \mathrm{~L}^{-1}\right]$ output was used).

849

\begin{tabular}{|r|c|c|c|}
\hline Parameter & Unit & Sensor type & Calibration \\
\hline Chlorophyll A & $\mathrm{mg} * \mathrm{~L}^{-1}$ & Optical, fluorescence & HPLC, cross \\
\hline Phycocyanin & Raw fluorescence & Optical, fluorescence & cross \\
\hline $\mathrm{fDOM}$ & Raw fluorescence & Optical, fluorescence $*$ & cross \\
\hline Dissolved oxygen & $\%$ saturation** & Optical, luminescence & Saturated air, cross \\
\hline Conductivity (specific) & $\mu \mathrm{S} * \mathrm{~cm}^{-1}$ & 4-electrode cell & Conductivity standard \\
\hline Temperature & ${ }^{\circ} \mathrm{C}$ & Thermistor & cross \\
\hline
\end{tabular}

850 
852 2. Statistical results of GAM-models testing time series of water parameters and metabolic

853 rates. Results are from individual models (one model per parameter and measurement period).

854 For mean and CV of water parameters, N per model is 768 for $\mathrm{t} 1-\mathrm{t} 3$ and 480 for $\mathrm{t} 4$ and $\mathrm{t} 5$. For

855 metabolic rates, $\mathrm{N}$ per model is 823 for $\mathrm{t} 1-\mathrm{t} 3$ and 5 for $\mathrm{t} 4$ and $\mathrm{t} 5$. Trends $(\mathrm{P}<0.1)$ indicated by

856 bold font; significant results $(\mathrm{P}<0.05)$ indicated by underlined bold font. $\mathrm{t}$-value $=$ model

857 estimate / model estimate $\mathrm{SD}, \mathrm{Rsq}=\mathrm{R}$ squared of model fit.

858

\begin{tabular}{|c|c|c|c|c|c|c|c|c|c|c|c|c|c|c|c|}
\hline & \multicolumn{3}{|c|}{ t1 } & \multicolumn{3}{|c|}{ t2 } & \multicolumn{3}{|c|}{ t3 } & \multicolumn{3}{|c|}{ t4 } & \multicolumn{3}{|c|}{ t5 } \\
\hline Mean & $\mathrm{t}$-value & P-value & Rsq & $\mathrm{t}$-value & P-value & Rsq & $t$-value & P-value & Rsq & t-value & P-value & Rsq & $\mathrm{t}$-value & P-value & Rsq \\
\hline Chlorophyll A & 1.724 & 0.085 & 0.809 & 2.696 & $\underline{0.007}$ & 0.945 & 0.355 & 0.722 & 0.863 & 3.14 & $\underline{0.001}$ & 0.916 & 3.6 & $\leq 0.001$ & 0.927 \\
\hline Phycocyanin & 0.311 & 0.756 & 0.748 & 0.637 & 0.524 & 0.752 & -0.445 & 0.656 & 0.865 & 0.006 & 0.995 & 0.883 & -0.727 & 0.467 & 0.875 \\
\hline fDOM & -0.302 & 0.762 & 0.641 & -4.923 & $\leq 0.001$ & 0.889 & -9.62 & $\leq 0.001$ & 0.963 & -6.69 & $\leq 0.001$ & 0.983 & -6.553 & $\leq 0.001$ & 0.966 \\
\hline Dissolved oxygen & -0.877 & 0.38 & 0.758 & 1.163 & 0.245 & 0.779 & -0.35 & 0.726 & 0.816 & -2.013 & $\underline{0.044}$ & 0.856 & -3.265 & $\underline{0.001}$ & 0.892 \\
\hline Temperature & -0.082 & 0.934 & 0.448 & 0.386 & 0.699 & 0.734 & -0.37 & 0.711 & 0.646 & 0.657 & 0.511 & 0.775 & -0.113 & 0.91 & 0.901 \\
\hline Conductivity & 2.064 & $\underline{0.039}$ & 0.968 & 0.112 & 0.911 & 0.939 & -1.165 & 0.244 & 0.907 & -0.533 & 0.594 & 0.875 & -0.019 & 0.985 & 0.884 \\
\hline $\mathbf{C V}$ & $\mathrm{t}$-value & P-value & Rsq & $\mathrm{t}$-value & P-value & Rsq & $t$-value & P-value & Rsq & t-value & P-value & Rsq & $\mathrm{t}$-value & P-value & Rsq \\
\hline Chlorophyll A & -2.041 & $\underline{0.041}$ & 0.784 & -3.31 & $\underline{0.001}$ & 0.799 & 1.578 & 0.115 & 0.551 & -0.388 & 0.698 & 0.661 & -2.803 & $\underline{0.005}$ & 0.734 \\
\hline Phycocyanin & -4.846 & $\leq 0.001$ & 0.668 & -2.092 & $\underline{0.037}$ & 0.557 & -1.354 & 0.176 & 0.621 & -2.105 & $\underline{0.035}$ & 0.541 & -1.886 & 0.059 & 0.696 \\
\hline fDOM & -0.052 & 0.958 & 0.508 & 1.119 & 0.263 & 0.357 & 4.036 & $\leq 0.001$ & 0.426 & 0.746 & 0.456 & 0.629 & 0.431 & 0.666 & 0.492 \\
\hline Dissolved oxygen & 0.244 & 0.808 & 0.617 & 1.186 & 0.236 & 0.558 & 0.949 & 0.343 & 0.319 & 0.566 & 0.571 & 0.363 & 0.312 & 0.755 & 0.404 \\
\hline Temperature & -0.233 & 0.816 & 0.324 & -0.253 & 0.801 & 0.446 & 0.914 & 0.361 & 0.257 & 0.193 & 0.847 & 0.415 & 0.886 & 0.376 & 0.43 \\
\hline Conductivity & -0.278 & 0.781 & 0.339 & -0.966 & 0.334 & 0.358 & 1.664 & 0.096 & 0.374 & -0.989 & 0.323 & 0.464 & -0.062 & 0.95 & 0.583 \\
\hline Metabolism & t-value & P-value & Rsq & $\mathrm{t}$-value & P-value & Rsq & $t$-value & P-value & Rsq & $\mathrm{t}$-value & P-value & Rsq & $\mathrm{t}$-value & P-value & Rsq \\
\hline GPP & -3.653 & $\leq 0.001$ & 0.705 & -1.165 & 0.249 & 0.461 & -2.147 & $\underline{0.036}$ & 0.169 & 1.381 & 0.176 & 0.046 & -3.395 & $\underline{0.002}$ & 0.406 \\
\hline $\mathrm{ER}$ & -3.47 & $\underline{0.001}$ & 0.329 & 0.121 & 0.905 & 0.545 & -0.367 & 0.36 & 0.456 & -0.415 & 0.681 & 0.235 & -0.346 & 0.34 & 0.23 \\
\hline GPP:ER & 0.16 & 0.874 & -0.033 & 1.816 & 0.074 & -0.005 & -4.812 & $\leq \mathbf{0 . 0 0 1}$ & 0.09 & -3.389 & $\underline{0.002}$ & 0.303 & -0.65 & 0.52 & 0.119 \\
\hline
\end{tabular}

